\title{
A Fuzzy Delphi-Analytical Hierarchy Process Approach for Ranking of Effective Material Selection Criteria
}

\author{
Sajad Kazemi, ${ }^{1}$ Seyed Mahdi Homayouni, ${ }^{2}$ and Jay Jahangiri ${ }^{3}$ \\ ${ }^{1}$ Department of Industrial Management, Faculty of Management and Accounting, Qazvin Branch, \\ Islamic Azad University, Qazvin 34185, Iran \\ ${ }^{2}$ Department of Industrial Engineering, Lenjan Branch, Islamic Azad University, Zarinshahr, Isfahan 84741, Iran \\ ${ }^{3}$ Department of Mathematical Sciences, Kent State University, Burton, OH 44021-9500, USA \\ Correspondence should be addressed to Seyed Mahdi Homayouni; homayouni@iauln.ac.ir
}

Received 19 December 2014; Revised 25 February 2015; Accepted 8 March 2015

Academic Editor: Marjan Bahraminasab

Copyright (C) 2015 Sajad Kazemi et al. This is an open access article distributed under the Creative Commons Attribution License, which permits unrestricted use, distribution, and reproduction in any medium, provided the original work is properly cited.

\begin{abstract}
The ability to select the most appropriate materials for a given application is the fundamental challenge faced by a design engineer. The objective of any material selection procedure is to identify appropriate selection criteria and to obtain the most appropriate combination of criteria in conjunction with requirements. Hence, selection of material is a multicriteria decision making problem. This study investigates and evaluates critical material selection criteria in a priority framework using the fuzzy Delphi-analytical hierarchy process method to overcome all shortcomings from AHP and Delphi methods that are common in material selection problem. 75 of the most important criteria for material selection have been collected from the literature. These criteria have been questioned in automobile interior design firms in Iran for car dashboard design. This ranking method would help product designers to decide on appropriate materials in a consistent method. Results indicate that "general" criteria such as availability, quality, risk, and technology are the most important criteria from the viewpoint of Iranian car manufacturers. Other criteria such as financial, technical, social and environmental, and sensorial criteria are relatively important in subsequent ranks.
\end{abstract}

\section{Introduction}

Many countries are moving towards the globalization of their economy in order to achieve lower cost of production and services. This trend is seen mostly in status of global production mostly in Asia and developing countries. Increasing the tendency for industrialization and globalization in developing countries has provided more opportunities for productive industries. On the other hand, these factors have influenced the environment and increased the environmental pressures on manufacturers [1].

Product design is the most strategic phase to control environmental impact during a product's life cycle, whereby designers play a significant role in reducing environmental impact from selection of materials, manufacturing processes, product usage, and end of life treatment [2]. Designing products that are easily recycled will support the effectiveness of the recycling process and thus will prolong material usage and support natural resources preservation. This must also be supported by the selection of high recyclable materials [2]. An ever increasing variety of materials is available today with each having its own characteristics, applications, advantages, and limitations [3].

With the availability of a large number of materials and to fulfill the requirements of the manufacturing industries, material selection today became quite a complicated task [4]. Improvement in production performance, reduction in costs, and environmental sensitivity are generally related to the selection of materials [5]. The complex interrelationships between a variety of materials and their selection criteria frequently make the material selection process a difficult and time consuming task. Hence, a systematic and efficient approach to material selection is necessary in order to select the best alternative for a product [6]. Material selection has great importance in the design and development of products and it is also critical for the success and competitiveness of 
the producers. Improper selection of materials may result in damage or failure of an assembly and significantly decreases the performance of products, thus negatively affecting productivity, profitability, and reputation of an organization [7].

Material selection criteria influence the selection of a material for a given application. These criteria include physical, mechanical, electrical, magnetic, chemical, and manufacturing properties (e.g., machinability, formability, weld ability, cast ability, and heat treatability). Moreover, cost, shape, environmental impact, performance characteristics, availability, fashion, market trends, cultural aspects, aesthetics, recycling, and target group are the other criteria taken into account in material selection [8]. Deng and Edwards [9] emphasized that the process of materials selection should be combined with structural optimization. Therefore, the ability to select the most appropriate material for a given application is the fundamental challenge faced by a design engineer which is a multicriteria decision making (MCDM) problem $[10,11]$. There is a need for simple, systematic, and logical methods or mathematical tools to guide decision makers in considering a number of selection attributes and their interrelations [3]. In order to address the issue of material selection and to increase the efficiency in design process, a variety of methods had been proposed in the literature [7].

The objective of any material selection procedure is to identify appropriate selection criteria and to obtain the most appropriate combination of criteria in conjunction with the real requirement. Efforts need to be extended to identify those criteria that influence material selection for a given engineering design to eliminate unsuitable alternatives and to select the most appropriate alternative using simple and logical methods [3]. This problem of choosing appropriate selection criteria requires a variety of expert opinions which are sometimes conflicting. Thus, using the existing MCDM methods may face some troubles in summing up the experts' opinions.

The objective of this study is to investigate and evaluate the key material selection criteria and to study the influence of these criteria on material assessment and selection in a priority framework using the fuzzy Delphi-analytical hierarchy process (FDAHP) method, especially for car dashboard in automobile interior design firms in Iran. This method would result in easier convergence of experts' opinions and using qualitative collection of material selection criteria. Perhaps, the proposed method can be used by designers to choose material selection criteria more effectively. Section 1 introduces the background and motivation of the research. The review of the literature related to material and selection methods is cited in Section 2. The process of the FDAHP method is described in Section 3. The results are presented in Section 4. Section 5 discusses the results and conclusion and implications are presented in Section 6.

\section{Literature Review}

Selecting the most appropriate materials for high technology components used in biomedical, aerospace, and nuclear industries is particularly demanding and important to get things right the first time [12]. An inappropriate selection of materials may result in damage or failure of an assembly and significantly decreases the performance. Mainly a large number of factors are influencing the selection process in a critical issue [13]. The selection of an optimal material for an engineering design from two or more alternative materials on the basis of two or more attributes is an MCDM process [9]. MCDM consists of generating alternatives, establishing criteria, evaluating alternatives, assessing criteria weights, and application of a ranking system [14]. Different MCDM methods regularly create different outcomes for selecting or ranking a set of alternative decisions involving multiple criteria [12]. Various approaches have been proposed by researchers to solve the problem of proper material selection [9]. Table 1 presents some of the most relevant and up to date researches performed in the past five years. The authors used these literatures to select the initial set of criteria for this research.

\section{Materials and Methods}

Here, in Section 3, details of an analytical framework for evaluation and choice of criteria for the material selection are presented. Selection criteria have been identified through reviewing the literature and using the opinions and experience of experts in an automobile interior design firm. Conflicting goals and decisions in an analytical framework force decision makers to use MCDM methods [20]. MCDM methodologies are rapidly growing in the material selection whereas a large number of factors are influencing the selection process [13]. One of the widely used MCDM techniques is the AHP where the assessment of preference is performed through ratio-scale pairwise comparisons of the decision elements. The AHP is a method widely used for facilitating decision making by organizing perceptions, feelings, judgments, and memories into a multilevel hierarchic structure that exhibits the forces that influence a decision [21]. It has been proved that AHP is one of the most widely applied multiple criteria decision making methods, which has been applied for solving unstructured problems in areas of engineering [22]. It is further suggested that AHP is about breaking a problem down and then aggregating the solutions of all the subproblems into a conclusion [23].

Decision makers offer their knowledge and information of all characteristics of the problem in order to set up the framework of the AHP analysis. However, the environment of the real world problems would make it hard for the decision makers to express their knowledge precisely, but they say it using fuzzy and ambiguous expressions. Fuzzy sets incorporated into pairwise comparison in AHP method would model this kind of ambiguousness of human knowledge. The fuzzy AHP allows more accurate description of uncertain and ambiguous knowledge of decision makers [24].

The traditional AHP method is problematic in that it uses an exact value to express the decision maker's opinion in a comparison of alternatives [25]. AHP method is often criticized due to its use of unbalanced scale of judgments and its inability to adequately handle the inherent uncertainty and imprecision in the pairwise comparison process [26]. The Delphi research method is a flexible research technique that has been successfully used to explore new concepts within and outside of the systems of knowledge [27]. This method 


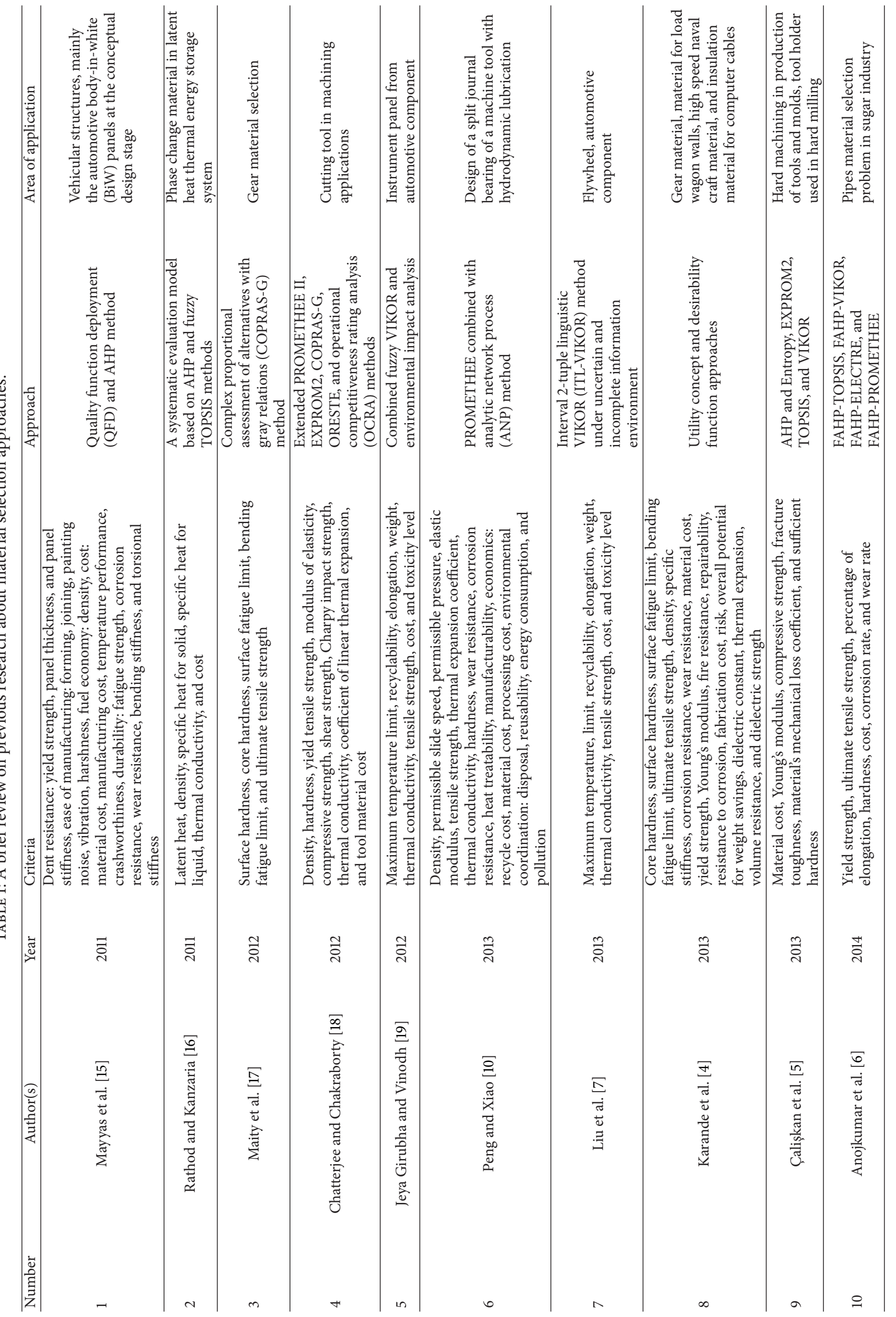




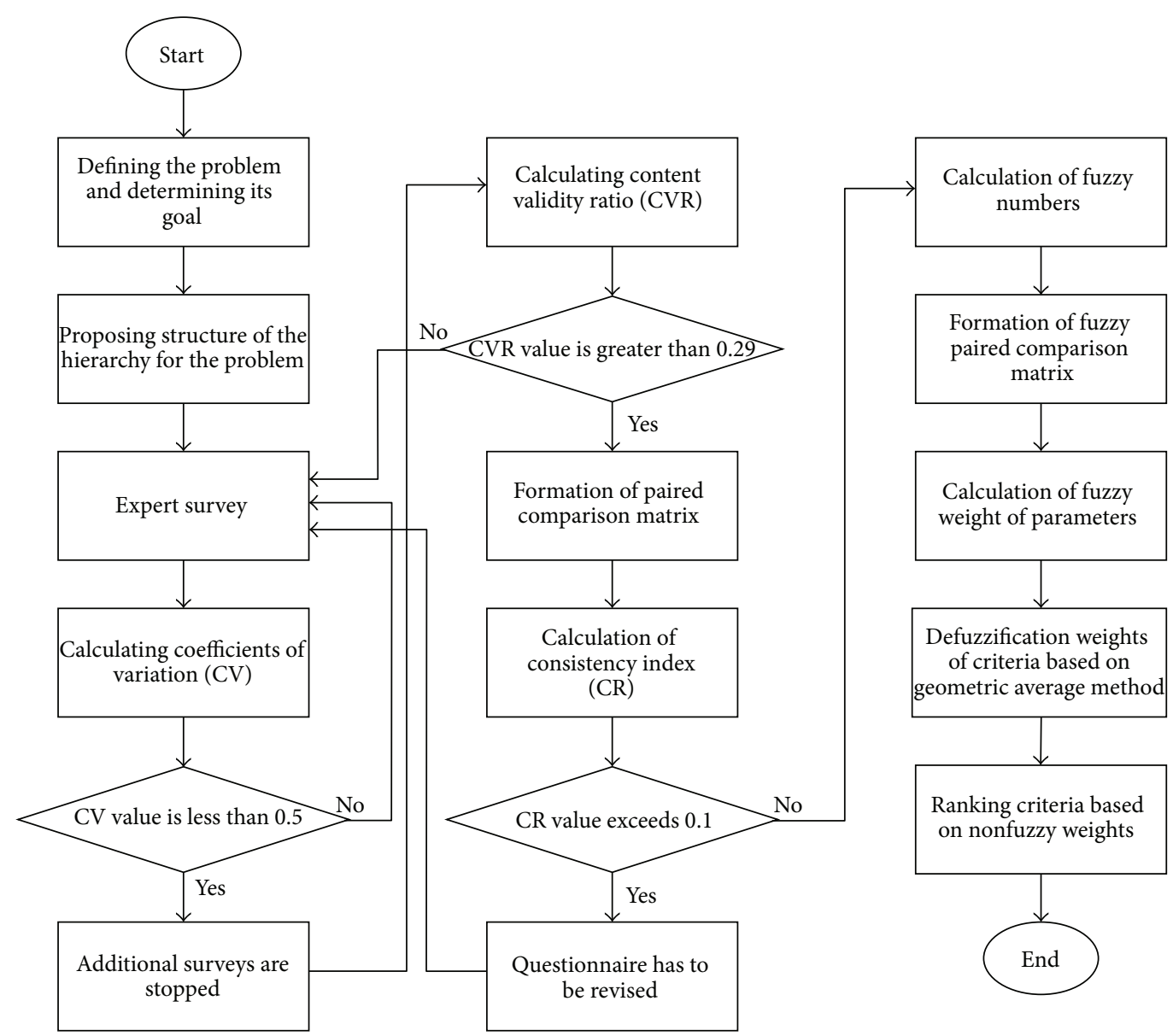

FIGURE 1: Flowchart of the proposed FDAHP methodology.

replaces traditional research approaches using statistical methods. Indeed, Delphi is a method for structuring a group relationship process in a way that allows group members to be challenged by the problem. It is an iterative process to collect and modify judgments of experts using a series of data collection, analysis techniques, and brainstorming for problems, opportunities, solutions, and forecasts.

Grisham [28] and Hsieh et al. [29] used the Delphi method to send and receive questionnaires and interviews with experts. Thus, the aim of this method is to use questionnaires and expert surveys with repeatedly given feedback. Traditional Delphi method always has suffered low convergence of expert opinions, high cost of administration, and probable elimination of opinions of some individuals [23]. To overcome all these shortcomings from AHP and Delphi methods, fuzzy Delphi-analytical hierarchy process was developed for the problem of material selection.

In the FDAHP methodology a systematic qualitative method is used to collect and converge expert users of a specific topic. This process of data gathering is performed through a set of carefully designed sequential questionnaires. This sequential set of questionnaires helps the respondents to be familiar with other opinions and may correct or change their initial estimations. It deals with imprecision and subjectivity in the pairwise comparison process. Using the fuzzy set theory helps the decision makers to express their vague opinions in terms of linguistic variables. The methodology uses a range of values to incorporate decision maker's uncertainty. From this range decision makers can select the values that reflect their confidence and also can specify their attitude as optimistic, pessimistic, or moderate [24]. The stepwise procedure of the FDAHP methodology after defining the problem and determining its goal is depicted in Figure 1 and details of its steps are described in steps (A) to (I), according to Liu and Chen [20] and Kim et al. [30].

(A) Proposing Structure of the Hierarchy. The hierarchy from the top (the objectives from a decision maker's viewpoint) through the intermediate levels (criteria on which subsequent levels depend) to the lowest level contains subcriteria and usually alternatives.

(B) Expert Survey. Experts are asked to rank (or assign scores to) the parameters influencing decision making in a qualitative or quantitative way if possible according to Table 2.

(C) Calculating Coefficients of Variation and Content Validity. Specifically, the coefficients of variation $(\mathrm{CV})$ for the expert surveys and content validity ratio (CVR) are analyzed in the methodology of this research. In this process, if the $\mathrm{CV}$ 
TABLE 2: The fundamental scale score.

\begin{tabular}{lcc}
\hline Symbol & Intensity of importance & Assigned numerical value \\
\hline WI & Without importance & $\mathbf{1}$ \\
LI & Low importance & $\mathbf{3}$ \\
MI & Moderate importance & $\mathbf{5}$ \\
SI & Strong importance & $\mathbf{7}$ \\
VEI & Very extreme importance & $\mathbf{9}$ \\
\hline
\end{tabular}

value is less than 0.5 , additional surveys are stopped [31]. The CVR developed by Lawshe [32] and recalculated by Wilson et al. [33] measures agreement among survey raters as to how essential a particular factor or item is. The CVR ranges from +1 to -1 . A higher positive value is used as an indicator that survey experts were in agreement that a factor or item was essential. Generally, a CVR that is greater than 0.29 can be considered to be an appropriate evaluation level. The coefficient of variation is the ratio of the standard deviation to the mean. Using the CV can make it easier to compare the overall precision of the data obtained, as shown in (1), in which "NE" is the number of survey experts indicating that a factor or item is "essential" and " $N$ " is the total number of survey experts:

$$
\mathrm{CVR}=\frac{(N E-N / 2)}{(N / 2)}
$$

(D) Formation of Paired Comparison Matrix. In this step opinions are considered directly from the survey to formation of paired comparison matrix.

(E) Calculation of Consistency Index. Determine whether the input data satisfies a "consistency check." If it does not, go back to Step B and redo the pairwise comparisons. In this step, the inconsistency of judgments through the matrix can be captured using the largest eigenvalue $\lambda_{\max }$. Given a $(n \times n)$ square matrix, a number $\left(\lambda_{\max }-n\right)$ measures the deviation of the judgments from the consistent approximation. The closer $\lambda_{\max }$ is to $n$, the more consistent is the result. The deviation of consistency is represented by the consistency index (CI) and then the consistency rate (CR) is calculated, which are defined in (2) and (3).

The random index (RI) is determined by the size of $n$ according to Alonso and Lamata [34]. Saaty [35] advised that $\mathrm{CR}$ is consistent in cases where it is smaller than or equal to 0.1 . If it exceeds 0.1 , the pairwise comparison needs to be done again or the questionnaire has to be revised:

$$
\begin{gathered}
\mathrm{CI}=\frac{\left(\lambda_{\max }-n\right)}{(n-1)}, \\
\mathrm{CR}=\frac{\mathrm{CI}}{\mathrm{RI}} .
\end{gathered}
$$

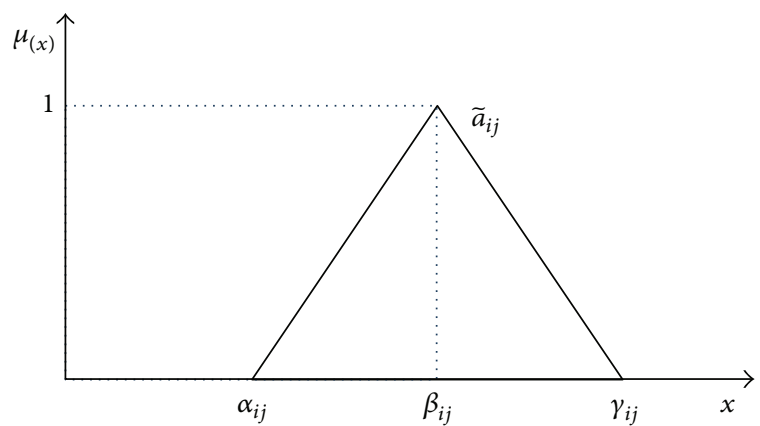

FIGURE 2: The triangle membership function of the fuzzy Delphi method.

(F) Calculation of Fuzzy Numbers. In order to calculate fuzzy numbers $\left(\alpha_{i j}\right)$, opinions resulting from survey are directly considered. Based on logic of triangle fuzzy numbers, maximum and minimum values of expert opinions are registered as boundary point and geometrical mean is recovered as membership degree of triangle fuzzy numbers. In this case, a fuzzy number is defined as presented in (4) to (7).

In (4) to (7), $\beta_{i j k}$ shows relative importance of parameter $i$ over parameter $j$ from viewpoint of $k$ th person, $\alpha_{i j}$ and $\gamma_{i j}$ are, respectively, lower and upper limits of opinions, and $\delta_{i j}$ is also geometrical mean of these opinions. It is obvious that fuzzy number components are defined in a way that $\alpha_{i j} \leq \delta_{i j} \leq \gamma_{i j}$ (Figure 2); these components vary in range $(1 / 9,9)$ :

$$
\begin{gathered}
\tilde{a}_{i j}=\left(\alpha_{i j}, \delta_{i j}, \gamma_{i j}\right), \\
\alpha_{i j}=\operatorname{Min}\left(\beta_{i j k}\right), \quad k=1,2, \ldots, n, \\
\delta_{i j}=\left[\prod_{k=1}^{n} \beta_{i j k}\right]^{1 / n}, \quad k=1,2, \ldots, n, \\
\gamma_{i j}=\operatorname{Max}\left(\beta_{i j k}\right), \quad k=1,2, \ldots, n .
\end{gathered}
$$

(G) Formation of Fuzzy Paired Comparison Matrix. In this step, based on fuzzy numbers obtained in previous step, fuzzy paired comparison matrix for parameters is formed as presented in (8) and matrix (9): 


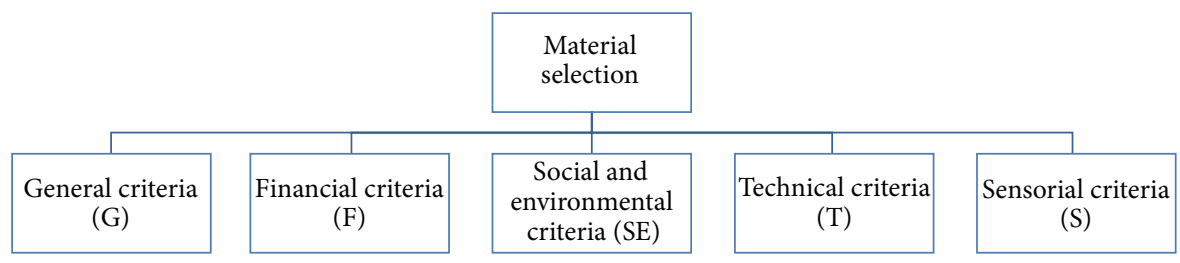

FIgURE 3: Main influencing criteria in material selection.

$$
\begin{aligned}
& \widetilde{A}=\left[\tilde{a}_{i j}\right]_{n \times n}, \quad \tilde{a}_{i j} \otimes \tilde{a}_{j i} \approx 1, \quad i, j=1,2, \ldots, n,
\end{aligned}
$$

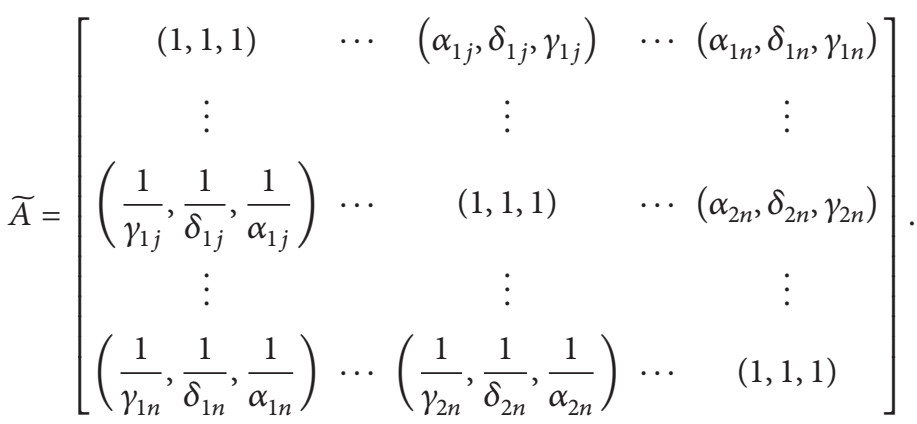

(H) Calculation of Fuzzy Weight of Parameters. Relative fuzzy weights of parameters are calculated using

$$
\widetilde{Z}_{i}=\left[\widetilde{a}_{i j} \otimes \cdots \otimes \widetilde{a}_{i n}\right]^{1 / n}, \quad \widetilde{W}_{i}=\widetilde{Z}_{i} \oslash\left(\widetilde{Z}_{i} \oplus \cdots \oplus \widetilde{Z}_{n}\right) .
$$

In these relations, $\otimes$ denotes multiplication, $\oplus$ denotes addition, and $\oslash$ denotes division of fuzzy numbers, in which $\widetilde{W}_{i}$ is a row vector consisting of a fuzzy weight of the $i$ th factor. If $\widetilde{M}$ and $\widetilde{N}$ (shown in (11)) are two fuzzy numbers, then fuzzy multiplication, addition, and division operators are shown in (12) to (14):

$$
\begin{gathered}
\widetilde{M}=\left(\alpha_{11}, \delta_{11}, \gamma_{11}\right), \quad \widetilde{N}=\left(\alpha_{12}, \delta_{12}, \gamma_{12}\right), \\
\widetilde{M} \oplus \widetilde{N}=\left(\alpha_{11}+\alpha_{12}, \delta_{11}+\delta_{12}, \gamma_{11}+\gamma_{12}\right), \\
\widetilde{M} \otimes \widetilde{N}=\left(\alpha_{11} \times \alpha_{12}, \delta_{11} \times \delta_{12}, \gamma_{11} \times \gamma_{12}\right), \\
\widetilde{M} \oslash \widetilde{N}=\left(\frac{\alpha_{11}}{\gamma_{12}}, \frac{\delta_{11}}{\delta_{12}}, \frac{\gamma_{11}}{\alpha_{12}}\right) .
\end{gathered}
$$

(I) Defuzzification Weights of Parameters. After finding the final weights of each parameter, all values obtained become nonfuzzy based on (15). The defuzzification is based on geometric average method; $W_{i}$ is a weight of the $i$ th factor:

$$
W_{i}=\left(\prod_{j=1}^{n} \widetilde{W}_{i j}\right)^{1 / n}
$$

\section{Case Study}

According to previous section, the first step in our research methodology after defining the problem and determining its goal is proposing the structure of the hierarchy. The evaluation criteria in our case study are identified for selection of the most appropriate material through the literature $[3,4,7,10$ $12,18,36-40]$ and experts in interior car design firms and faculties of universities. After the identification of the evaluation criteria, decision making team determines five main influencing criteria and seventy-five influencing subcriteria for the evaluation process. The identified evaluation criteria are shown in Figures 3 and 4 . For the purpose of this paper, first these five main criteria are ranked; and then in each column the rank of each subcriterion is determined due to its weight from FDAHP methodology.

For the criteria suggested in automobile interior design, the stylist responsible for the design of the automobile interior develops the proportions, shape, placement, and surfaces for the instrument panel, dashboard, seats, door trim panels, headliner, pillar trims, and so forth. Emphasis of the research is on the selection of material in dashboard design (see Figure 5).

\section{Results and Discussion}

Different decision makers have varying objectives and expectations and their judgment is influenced by criteria in material selection from different viewpoints. So, affecting criteria have different importance levels for different consumers. For this reason, 10 decision makers that worked on design 


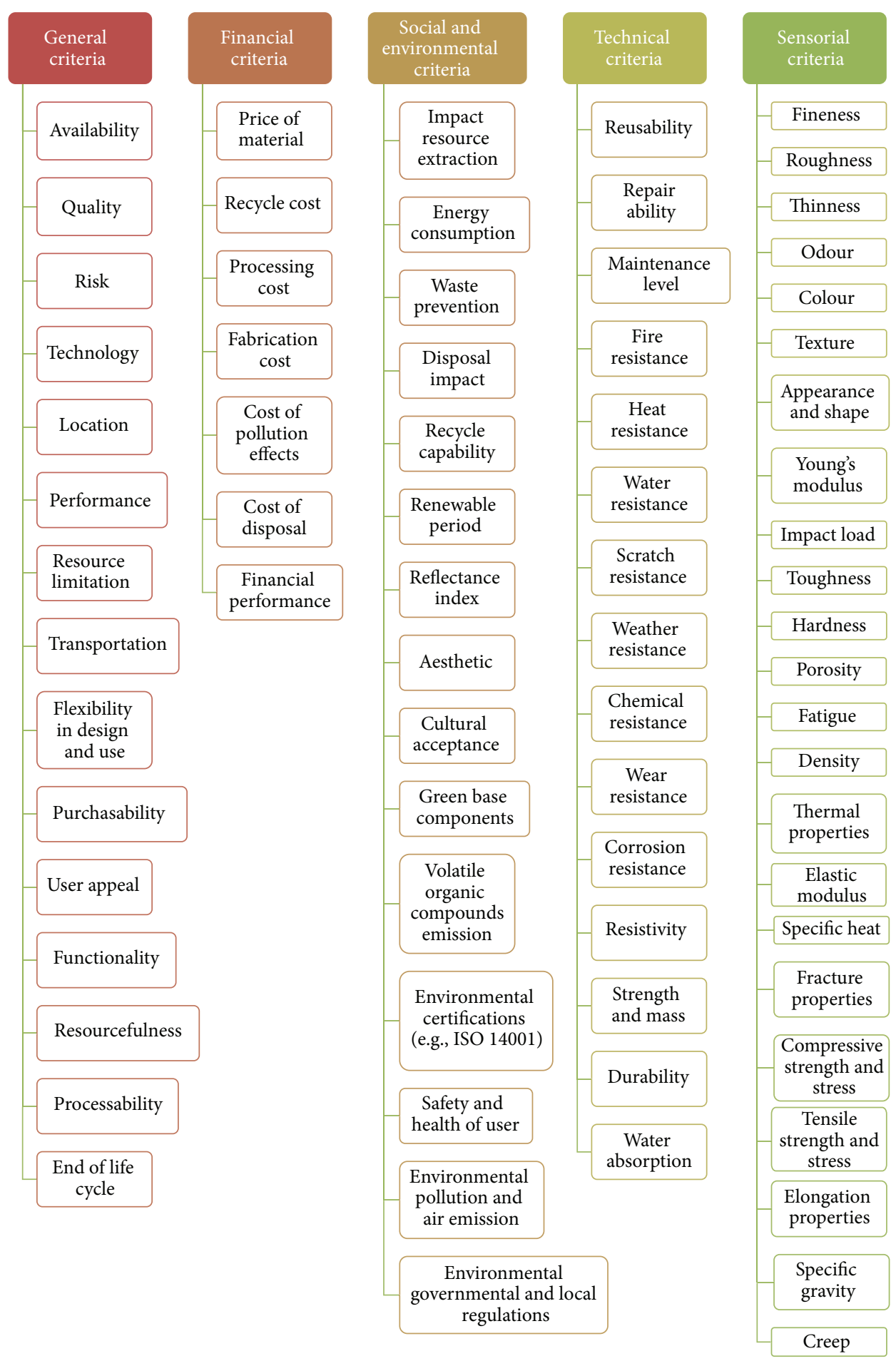

FIGURE 4: Main influencing subcriteria in material selection.

and produce car dashboard are selected from a variety of firms (automobile interior design firms) and universities for evaluation of the criteria. FDAHP method is proposed to take the decision makers subjective judgments into consideration and to reduce the uncertainty and vagueness in the decision process and to get a close-to-accurate decision maker (DM) opinion.
Firstly, each decision maker individually evaluates each criterion or subcriterion in its level by using scale in Table 2 (e.g., see Tables 3 and 4 for one decision maker evaluation). Similarly, evaluation scores from each decision maker have been collected for financial groups, social and environmental groups, technical groups, and sensorial groups of subcriteria levels. 
TABLE 3: Score parameters influencing decision in main criteria level.

\begin{tabular}{lccccc}
\hline Decision maker & G & F & SE & T & \\
\hline 1 & 9 & 7 & 5 & 7 & \\
\hline
\end{tabular}

TABLE 4: Score parameters influencing decision in subcriteria level for the general group.

\begin{tabular}{cccccccccccccccc}
\hline DM & G1 & G2 & G3 & G4 & G5 & G6 & G7 & G8 & G9 & G10 & G11 & G12 & G13 & G14 & G15 \\
\hline 1 & 7 & 7 & 3 & 7 & 5 & 7 & 5 & 5 & 7 & 5 & 3 & 5 & 5 & 5 & 5 \\
\hline
\end{tabular}

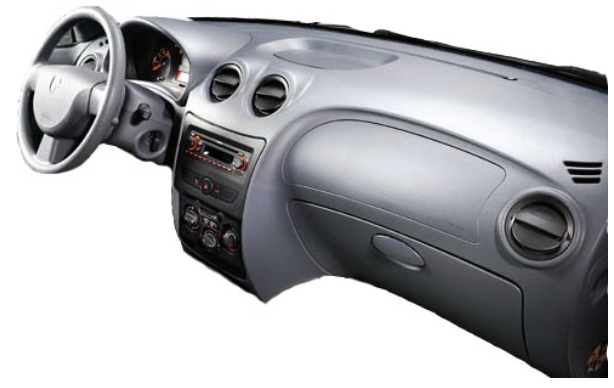

FIGURE 5: Runna automobile dashboard from Iran-Khodro automobile industry [41].

TABLE 5: CV and CVR results of final evaluation criteria.

\begin{tabular}{lcc}
\hline Criteria and subcriteria & CV & CVR \\
\hline General criteria & 0.09 & 0.6 \\
Financial criteria & 0.14 & 0.4 \\
Social and environmental criteria & 0.21 & 0.4 \\
Technical criteria & 0.15 & 0.6 \\
Sensorial criteria & 0.25 & 0.4 \\
\hline
\end{tabular}

TABLE 6: Paired comparison matrix for main criteria level.

\begin{tabular}{ccccccc}
\hline Decision maker & Criteria & $\mathrm{G}$ & $\mathrm{F}$ & $\mathrm{SE}$ & $\mathrm{T}$ & $\mathrm{S}$ \\
\hline \multirow{4}{*}{1} & $\mathrm{G}$ & 1 & 1.286 & 1.8 & 1.286 & 1.8 \\
& $\mathrm{~F}$ & 0.778 & 1 & 1.4 & 1 & 1.4 \\
& $\mathrm{SE}$ & 0.556 & 0.714 & 1 & 0.714 & 1 \\
& $\mathrm{~T}$ & 0.778 & 1 & 1.4 & 1 & 1.4 \\
& $\mathrm{~S}$ & 0.556 & 0.714 & 1 & 0.714 & 1 \\
\hline
\end{tabular}

Decision makers from different backgrounds may define different weight vectors. They usually cause not only the imprecise evaluation but also serious persecution during decision process. For this reason, CV and CVR indices have been calculated to stop additional surveys in an appropriate evaluation level (see Table 5). In the next step, the consistency index and the consistency ratio have been calculated to improve pairwise comparison. The paired comparison matrix for each expert and geometric mean of paired comparison matrixes (GMPCM) are calculated to compute and confirm consistency rate (see Table 6 for first expert and main criteria level).

Similarly, paired comparison matrices for all subcriteria have been calculated and the reliability of the expert's survey in the paired comparisons matrix is confirmed $(\mathrm{CR} \leq 0.1)$,
TABLE 7: Consistency index and consistency rate from pairwise comparison.

\begin{tabular}{lcc}
\hline Decision maker & CI & CR \\
\hline 1 & 0.00 & 0.00 \\
All & 0.00 & 0.00 \\
\hline
\end{tabular}

using consistency index and consistency rate, defined in (2) and (3). For example, Table 7 shows these two indices in the main level for first DM and for all DM (GMPCM).

After creating pairwise comparison matrices and confirming their reliability, fuzzy numbers have been calculated using (4) to (7) and experts' opinions in a fuzzy framework have been defined. In the next step, the fuzzy Delphi paired comparison matrix for experts has been created using (6) and using the opinions from the converted survey to fuzzy numbers. Table 8 is an example of the results for the criteria listed in the main level.

Relative fuzzy weights were calculated in the next step using (10); and finally crisp weights for each criterion and subcriterion were calculated using (15) (defuzzification process). The ranking of all criteria and subcriteria is performed in their level and group considering these crisp weights. For example, Table 9 shows the results of fuzzy and crisp weights and also the ranking scores for each criterion in the main level. Similarly, fuzzy and crisp weights and ranking scores for other subcriteria and sublevels and their groups have been calculated and are presented in Tables 10-14.

As results show, in material selection "general" criteria listed in Figure 4 are the most important and effective among other main criteria followed by financial, technical, social-environmental, and sensorial criteria. These results are especially applicable for car dashboard in automobile interior design firms in Iran. This means that, in this case study, availability is the most important criterion followed by flexibility in design, quality, technology, purchase-ability, resource limitation, functionality, end of life cycle, performance, transportation, process-ability, resourcefulness, user appeal, risk, and location.

\section{Conclusions}

Decision makers usually select the best alternative based on ranking orders of a selected MCDM method, whereas different MCDM methods often produce different outcomes for ranking a set of alternative decisions. Material selection problems in the engineering design processes and a new 
TABLE 8: Fuzzy Delphi paired comparison matrix for decision makers.

\begin{tabular}{lcccccccccccccccc}
\hline \multirow{2}{*}{ Criteria } & & $\mathrm{G}$ & \multicolumn{3}{c}{$\mathrm{F}$} & \multicolumn{3}{c}{$\mathrm{SE}$} & \multicolumn{2}{c}{$\mathrm{T}$} & \multicolumn{2}{c}{$\mathrm{S}$} \\
& $\alpha$ & $\delta$ & $\gamma$ & $\alpha$ & $\delta$ & $\gamma$ & $\alpha$ & $\delta$ & $\gamma$ & $\alpha$ & $\delta$ & $\gamma$ & $\alpha$ & $\delta$ & $\gamma$ \\
\hline $\mathrm{G}$ & 1 & 1 & 1 & 1 & 1.353 & 1.8 & 1 & 1.684 & 3 & 1 & 1.6 & 1.8 & 1.4 & 2.448 & 3 \\
$\mathrm{~F}$ & 0.556 & 0.739 & 1 & 1 & 1 & 1 & 1 & 1.245 & 1.667 & 0.714 & 1.183 & 1.4 & 1.4 & 1.81 & 2.333 \\
$\mathrm{SE}$ & 0.333 & 0.594 & 1 & 0.6 & 0.803 & 1 & 1 & 1 & 1 & 0.6 & 0.95 & 1.4 & 1 & 1.453 & 1.667 \\
$\mathrm{~T}$ & 0.556 & 0.625 & 1 & 0.714 & 0.845 & 1.4 & 0.714 & 1.052 & 1.667 & 1 & 1 & 1 & 1 & 1.529 & 2.333 \\
$\mathrm{~S}$ & 0.333 & 0.409 & 0.714 & 0.429 & 0.553 & 0.714 & 0.6 & 0.688 & 1 & 0.429 & 0.654 & 1 & 1 & 1 & 1 \\
\hline
\end{tabular}

TABLE 9: Fuzzy and crisp weights and ranking scores for criteria in the main level.

\begin{tabular}{lcccc}
\hline Criteria and subcriteria & & Fuzzy weights $\left(\widetilde{W}_{i}\right)$ & & Nonfuzzy weights $\left(W_{i}\right)$ \\
\hline General criteria & 0.157 & 0.297 & 0.503 & 0.2859 \\
Financial criteria & 0.13 & 0.22 & 0.359 & 0.2174 \\
Social and environmental criteria & 0.096 & 0.176 & 0.303 & 0.1724 \\
Technical criteria & 0.114 & 0.186 & 0.359 & 0.1965 \\
Sensorial criteria & 0.076 & 0.121 & 0.224 & 0.1277 \\
\hline
\end{tabular}

TABLE 10: Fuzzy and crisp weights and ranking scores for subcriteria in general group.

\begin{tabular}{|c|c|c|c|c|c|c|}
\hline Criteria & Subcriteria & & $\widetilde{W}_{i}$ & & $W_{i}$ & Ranking \\
\hline \multirow{15}{*}{ G } & G1 & 0.05738 & 0.09547 & 0.16253 & 0.09620 & 1 \\
\hline & G2 & 0.05277 & 0.08634 & 0.13293 & 0.08461 & 3 \\
\hline & G3 & 0.02462 & 0.04098 & 0.07927 & 0.04308 & 13 \\
\hline & G4 & 0.05277 & 0.08634 & 0.13293 & 0.08461 & 3 \\
\hline & G5 & 0.02340 & 0.04098 & 0.08286 & 0.04299 & 15 \\
\hline & G6 & 0.03033 & 0.06371 & 0.12563 & 0.06238 & 9 \\
\hline & G7 & 0.04263 & 0.07547 & 0.12998 & 0.07478 & 6 \\
\hline & G8 & 0.03769 & 0.06167 & 0.09495 & 0.06043 & 10 \\
\hline & G9 & 0.05548 & 0.09079 & 0.15199 & 0.09149 & 2 \\
\hline & G10 & 0.04288 & 0.07547 & 0.12998 & 0.07492 & 5 \\
\hline & G11 & 0.02462 & 0.04098 & 0.07927 & 0.04308 & 13 \\
\hline & G12 & 0.03942 & 0.06597 & 0.11619 & 0.06710 & 7 \\
\hline & G13 & 0.02589 & 0.05028 & 0.08573 & 0.04815 & 12 \\
\hline & G14 & 0.02679 & 0.05956 & 0.11550 & 0.05911 & 11 \\
\hline & G15 & 0.03942 & 0.06597 & 0.11619 & 0.06710 & 7 \\
\hline
\end{tabular}

TABLE 11: Fuzzy and crisp weights and ranking scores for subcriteria in financial group.

\begin{tabular}{ccccccc}
\hline Criteria & Subcriteria & & $\widetilde{W}_{i}$ & $W_{i}$ & Ranking \\
\hline \multirow{4}{*}{ F1 } & 0.11576 & 0.18864 & 0.31217 & 0.18961 & 0.12311 \\
& F2 & 0.07515 & 0.12395 & 0.20033 & 0.15712 & 4 \\
F3 & 0.08782 & 0.15950 & 0.27691 & 0.16419 & 0.09336 \\
& F4 & 0.10021 & 0.15950 & 0.27691 & 0.08458 & 6 \\
& F5 & 0.05218 & 0.09447 & 0.16510 & 0.18735 \\
\hline
\end{tabular}


TABLE 12: Fuzzy and crisp weights and ranking scores for subcriteria in social and environmental group.

\begin{tabular}{|c|c|c|c|c|c|c|}
\hline Criteria & Subcriteria & & $\widetilde{W}_{i}$ & & $W_{i}$ & Ranking \\
\hline \multirow{15}{*}{$\mathrm{SE}$} & SE1 & 0.03524 & 0.05540 & 0.08655 & 0.05529 & 9 \\
\hline & SE2 & 0.05630 & 0.09499 & 0.16512 & 0.09593 & 2 \\
\hline & SE3 & 0.05725 & 0.09499 & 0.15968 & 0.09540 & 3 \\
\hline & SE4 & 0.04350 & 0.07020 & 0.11412 & 0.07037 & 5 \\
\hline & SE5 & 0.06121 & 0.09988 & 0.16238 & 0.09976 & 1 \\
\hline & SE6 & 0.03524 & 0.05540 & 0.08655 & 0.05529 & 9 \\
\hline & SE7 & 0.02700 & 0.04830 & 0.10234 & 0.05215 & 12 \\
\hline & SE8 & 0.02778 & 0.05002 & 0.08227 & 0.04857 & 13 \\
\hline & SE9 & 0.03524 & 0.05540 & 0.08655 & 0.05529 & 9 \\
\hline & SE10 & 0.02656 & 0.05002 & 0.08085 & 0.04754 & 14 \\
\hline & SE11 & 0.02656 & 0.05002 & 0.08085 & 0.04754 & 14 \\
\hline & SE12 & 0.04350 & 0.07020 & 0.11412 & 0.07037 & 5 \\
\hline & SE13 & 0.05352 & 0.08031 & 0.12694 & 0.08171 & 4 \\
\hline & SE14 & 0.04067 & 0.06563 & 0.10492 & 0.06542 & 7 \\
\hline & SE15 & 0.03604 & 0.05926 & 0.09793 & 0.05936 & 8 \\
\hline
\end{tabular}

TABLE 13: Fuzzy and crisp weights and ranking scores for subcriteria in technical group.

\begin{tabular}{|c|c|c|c|c|c|c|}
\hline Criteria & Subcriteria & & $\widetilde{W}_{i}$ & & $W_{i}$ & Ranking \\
\hline \multirow{15}{*}{$\mathrm{T}$} & $\mathrm{T} 1$ & 0.04612 & 0.09441 & 0.19077 & 0.09400 & 1 \\
\hline & $\mathrm{T} 2$ & 0.04460 & 0.08978 & 0.18448 & 0.09040 & 2 \\
\hline & T3 & 0.04386 & 0.08538 & 0.17841 & 0.08742 & 3 \\
\hline & $\mathrm{T} 4$ & 0.03604 & 0.07591 & 0.15776 & 0.07558 & 5 \\
\hline & T5 & 0.03370 & 0.07097 & 0.15084 & 0.07119 & 9 \\
\hline & T6 & 0.01106 & 0.04059 & 0.09725 & 0.03521 & 13 \\
\hline & $\mathrm{T} 7$ & 0.03295 & 0.06635 & 0.13790 & 0.06705 & 11 \\
\hline & $\mathrm{T} 8$ & 0.01106 & 0.03665 & 0.09144 & 0.03334 & 14 \\
\hline & T9 & 0.02251 & 0.05057 & 0.10883 & 0.04985 & 12 \\
\hline & $\mathrm{T} 10$ & 0.03446 & 0.07097 & 0.15084 & 0.07172 & 8 \\
\hline & T11 & 0.03370 & 0.07097 & 0.17649 & 0.07501 & 7 \\
\hline & T12 & 0.03295 & 0.06635 & 0.14103 & 0.06799 & 10 \\
\hline & $\mathrm{T} 13$ & 0.03624 & 0.07591 & 0.15426 & 0.07515 & 6 \\
\hline & T14 & 0.03706 & 0.08119 & 0.17649 & 0.08098 & 4 \\
\hline & $\mathrm{T} 15$ & 0.00776 & 0.02398 & 0.05805 & 0.02511 & 15 \\
\hline
\end{tabular}

model that covered the most important criteria in material selection are presented.

Delphi and AHP are two common, important, and functional methods in MCDM but have their own shortcomings. The fuzzy Delphi-analytical hierarchy process method is applied to overcome these shortcomings in a fuzzy environment. In this method, experts' opinions are converged to an appropriate set of criteria.

The FDAHP methodology is a quantitative forecasting method that involves the systematic solicitation and collation of experts and general users on a particular topic through a set of carefully designed sequential questionnaires interspersed with summarized information and feedback of opinions derived from earlier responses. It deals with imprecision and subjectivity in the pairwise comparison processes. Considering the fuzziness in the decision data and futuristic decision making processes strengthens the comprehensiveness and reasonableness of the futuristic decision making processes. The methodology uses a range of values to incorporate decision makers' uncertainty. From this range, decision makers can select the values that reflect their confidence and also can specify their attitude like optimistic, pessimistic, or moderate.

The proposed method can provide solutions and guide for designers to expand their design alternatives. Results of applied example show the potential of the proposed FDAHP in MCDM. So it can help the designers and decision makers in acquiring more strong decisions, especially in automobile interior design material selection applications such as car dashboard. Results show that general criteria listed in Figure 4 are the most important set of criteria. Moreover, the financial, technical, social and environmental, and sensorial criteria are relatively important in subsequent ranks from 
TABLE 14: Fuzzy and crisp weights and ranking scores for subcriteria in sensorial group.

\begin{tabular}{|c|c|c|c|c|c|c|}
\hline Criteria & Subcriteria & & $\widetilde{W}_{i}$ & & $W_{i}$ & Ranking \\
\hline \multirow{23}{*}{ S } & S1 & 0.02749 & 0.05399 & 0.10739 & 0.05422 & 1 \\
\hline & S2 & 0.01892 & 0.03788 & 0.07597 & 0.03790 & 18 \\
\hline & S3 & 0.02490 & 0.05134 & 0.10185 & 0.05068 & 6 \\
\hline & S4 & 0.01778 & 0.03788 & 0.07267 & 0.03658 & 19 \\
\hline & S5 & 0.01441 & 0.02788 & 0.05701 & 0.02840 & 22 \\
\hline & S6 & 0.02669 & 0.05134 & 0.09891 & 0.05137 & 5 \\
\hline & S7 & 0.01425 & 0.02788 & 0.05573 & 0.02808 & 23 \\
\hline & S8 & 0.01495 & 0.03088 & 0.07057 & 0.03294 & 21 \\
\hline & S9 & 0.02383 & 0.04487 & 0.08545 & 0.04504 & 11 \\
\hline & S10 & 0.02809 & 0.05134 & 0.10335 & 0.05302 & 3 \\
\hline & S11 & 0.02809 & 0.05134 & 0.10335 & 0.05302 & 3 \\
\hline & S12 & 0.01763 & 0.03658 & 0.09253 & 0.03908 & 15 \\
\hline & S13 & 0.01954 & 0.04557 & 0.10200 & 0.04495 & 12 \\
\hline & S14 & 0.01858 & 0.04334 & 0.09183 & 0.04197 & 13 \\
\hline & S15 & 0.01831 & 0.04052 & 0.07934 & 0.03890 & 16 \\
\hline & S16 & 0.02490 & 0.05134 & 0.10185 & 0.05068 & 6 \\
\hline & S17 & 0.01831 & 0.04052 & 0.07934 & 0.03890 & 16 \\
\hline & S18 & 0.02573 & 0.04800 & 0.09193 & 0.04842 & 9 \\
\hline & S19 & 0.02573 & 0.04800 & 0.09193 & 0.04842 & 9 \\
\hline & S20 & 0.02555 & 0.05399 & 0.11113 & 0.05352 & 2 \\
\hline & S21 & 0.02462 & 0.04800 & 0.09747 & 0.04869 & 8 \\
\hline & S22 & 0.01522 & 0.03420 & 0.07597 & 0.03477 & 20 \\
\hline & S23 & 0.01602 & 0.04334 & 0.09533 & 0.04045 & 14 \\
\hline
\end{tabular}

the viewpoint of the Iranian car manufactures in car dashboard design. Their opinions have been affected by the conditions of Iranian economy, available production technology of the materials, and their availability.

\section{Conflict of Interests}

The authors declare that there is no conflict of interests regarding the publication of this paper.

\section{References}

[1] R. K. Mavi, S. Kazemi, A. F. Najafabadi, and H. B. Mousaabadi, "Identification and assessment of logistical factors to evaluate a green supplier using the fuzzy logic DEMATEL method," Polish Journal of Environmental Studies, vol. 22, no. 2, pp. 445-455, 2013.

[2] N. Sakundarini, Z. Taha, S. H. Abdul-Rashid, and R. A. Raja Ghazilla, "Incorporation of high recyclability material selection in computer aided design," Materials and Design, vol. 56, pp. 740-749, 2014.

[3] R. V. Rao and B. K. Patel, "A subjective and objective integrated multiple attribute decision making method for material selection," Materials and Design, vol. 31, no. 10, pp. 4738-4747, 2010.

[4] P. Karande, S. K. Gauri, and S. Chakraborty, "Applications of utility concept and desirability function for materials selection," Materials and Design, vol. 45, pp. 349-358, 2013.
[5] H. Çalişkan, B. Kurşuncu, C. Kurbanoĝlu, and Ş. Y. Güven, "Material selection for the tool holder working under hard milling conditions using different multi criteria decision making methods," Materials and Design, vol. 45, pp. 473-479, 2013.

[6] L. Anojkumar, M. Ilangkumaran, and V. Sasirekha, "Comparative analysis of MCDM methods for pipe material selection in sugar industry," Expert Systems with Applications, vol. 41, no. 6, pp. 2964-2980, 2014.

[7] H. C. Liu, L. Liu, and J. Wu, "Material selection using an interval 2-tuple linguistic VIKOR method considering subjective and objective weights," Materials and Design, vol. 52, pp. 158-167, 2013.

[8] P. Chatterjee, V. M. Athawale, and S. Chakraborty, "Selection of materials using compromise ranking and outranking methods," Materials and Design, vol. 30, no. 10, pp. 4043-4053, 2009.

[9] Y. M. Deng and K. L. Edwards, "The role of materials identification and selection in engineering design," Materials and Design, vol. 28, no. 1, pp. 131-139, 2007.

[10] A.-H. Peng and X.-M. Xiao, "Material selection using PROMETHEE combined with analytic network process under hybrid environment," Materials and Design, vol. 47, pp. 643652, 2013.

[11] M.-S. Liao, G.-S. Liang, and C.-Y. Chen, "Fuzzy grey relation method for multiple criteria decision-making problems," Quality \& Quantity, vol. 47, no. 6, pp. 3065-3077, 2013.

[12] D. Das, Selection of materials in engineering design using ashby's chart and AHP-TOPSIS [M.S. thesis], Jadavpur University, Kolkata, India, 2012, http://dspace.jdvu.ac.in/handle/123456789/ 24194. 
[13] P. Chatterjee, V. M. Athawale, and S. Chakraborty, "Materials selection using complex proportional assessment and evaluation of mixed data methods," Materials \& Design, vol. 32, no. 2, pp. 851-860, 2011.

[14] J. R. S. C. Mateo, "Multi-criteria analysis," in Multi Criteria Analysis in the Renewable Energy Industry, Green Energy and Technology, pp. 7-10, Springer, London, UK, 2012.

[15] A. Mayyas, Q. Shen, M. abdelhamid, D. Shan, A. Qattawi, and M. Omar, "Using quality function deployment and analytical hierarchy process for material selection of Body-In-White," Materials and Design, vol. 32, no. 5, pp. 2771-2782, 2011.

[16] M. K. Rathod and H. V. Kanzaria, "A methodological concept for phase change material selection based on multiple criteria decision analysis with and without fuzzy environment," Materials and Design, vol. 32, no. 6, pp. 3578-3585, 2011.

[17] S. R. Maity, P. Chatterjee, and S. Chakraborty, "Cutting tool material selection using grey complex proportional assessment method," Materials and Design, vol. 36, pp. 372-378, 2012.

[18] P. Chatterjee and S. Chakraborty, "Material selection using preferential ranking methods," Materials and Design, vol. 35, pp. 384-393, 2012.

[19] R. Jeya Girubha and S. Vinodh, "Application of fuzzy VIKOR and environmental impact analysis for material selection of an automotive component," Materials and Design, vol. 37, pp. 478486, 2012.

[20] Y.-C. Liu and C.-S. Chen, "A new approach for application of rock mass classification on rock slope stability assessment," Engineering Geology, vol. 89, no. 1-2, pp. 129-143, 2007.

[21] T. L. Saaty, "How to make a decision: the analytic hierarchy," Interfaces, vol. 24, pp. 19-43, 1994.

[22] C. W. Chang, C. R. Wu, C. T. Lin, and H. C. Chen, "An application of AHP and sensitivity analysis for selecting the best slicing machine," Computers and Industrial Engineering, vol. 52, no. 2, pp. 296-307, 2007.

[23] R. Joshi, D. K. Banwet, and R. Shankar, "A Delphi-AHP-TOPSIS based benchmarking framework for performance improvement of a cold chain," Expert Systems with Applications, vol. 38, no. 8, pp. 10170-10182, 2011.

[24] V. Saxena, M. Jain, P. Singh, and P. K. Saxena, Fuzzy Delphi Hierarchy Process and Its Application to Improve Indian Telemedical Services, 2010, http://www.isahp.org/2009Proceedings/Final_Papers/77_Saxena_FuzzyDelphiHierarchyProcessIndianTelemedicine_REV_FIN.pdf.

[25] T.-C. Wang and Y.-H. Chen, "Applying consistent fuzzy preference relations to partnership selection," Omega, vol. 35, no. 4, pp. 384-388, 2007.

[26] R. Mikaeil, M. Ataei, and R. Yousefi, "Evaluating the power consumption in carbonate rock sawing porocess by using FDAHP and TOPSIS techniques," in Efficient Decision Support Systems-Practice and Challenges in Multidisciplinary Domains, pp. 413-436, InTech, 2011.

[27] G. J. Skulmoski, F. T. Hartman, and J. Krahn, "The Delphi method for graduate research," Journal of Information Technology Education, vol. 6, pp. 1-21, 2007.

[28] T. Grisham, "The Delphi technique: a method for testing complex and multifaceted topics," International Journal of Managing Projects in Business, vol. 2, no. 1, pp. 112-130, 2009.

[29] L.-F. Hsieh, J.-B. Chin, and M.-C. Wu, "Performance evaluation for university electronic libraries in Taiwan," Electronic Library, vol. 24, no. 2, pp. 212-224, 2006.
[30] M. Kim, Y.-C. Jang, and S. Lee, "Application of Delphi-AHP methods to select the priorities of WEEE for recycling in a waste management decision-making tool," Journal of Environmental Management, vol. 128, pp. 941-948, 2013.

[31] J. S. Dajani, M. Z. Sincoff, and W. K. Talley, "Stability and agreement criteria for the termination of Delphi studies," Technological Forecasting and Social Change, vol. 13, no. 1, pp. 83-90, 1979.

[32] C. H. Lawshe, "A quantitative approach to content validity," Personnel Psychology, vol. 28, no. 4, pp. 563-575, 1975.

[33] F. R. Wilson, W. Pan, and D. A. Schumsky, "Recalculation of the critical values for Lawshe's content validity ratio," Measurement and Evaluation in Counseling and Development, vol. 45, no. 3, pp. 197-210, 2012.

[34] J. A. Alonso and M. T. Lamata, "Consistency in the analytic hierarchy process: a new approach," International Journal of Uncertainty, Fuzziness and Knowlege-Based Systems, vol. 14, no. 4, pp. 445-459, 2006.

[35] T. L. Saaty, The Analytic Hierarchy Process: Planning, Priority Setting, Resource Allocation, RWS Publications, Pittsburgh, Pa, USA, 1996.

[36] A. Shanian and O. Savadogo, "A methodological concept for material selection of highly sensitive components based on multiple criteria decision analysis," Expert Systems with Applications, vol. 36, no. 2, pp. 1362-1370, 2009.

[37] G. Tuzkaya, B. Gülsün, C. Kahraman, and D. Özgen, "An integrated fuzzy multi-criteria decision making methodology for material handling equipment selection problem and an application," Expert Systems with Applications, vol. 37, no. 4, pp. 28532863, 2010.

[38] K. S. Khor and Z. M. Udin, "Reverse logistics in Malaysia: investigating the effect of green product design and resource commitment," Resources, Conservation and Recycling, vol. 81, pp. 71-80, 2013.

[39] I. Ogunkah and J. Yang, "Investigating factors affecting material selection: the impacts on green vernacular building materials in the design-decision making process," Buildings, vol. 2, no. 1, pp. $1-32,2012$.

[40] A. Jahan, F. Mustapha, S. M. Sapuan, M. Y. Ismail, and M. Bahraminasab, "A framework for weighting of criteria in ranking stage of material selection process," International Journal of Advanced Manufacturing Technology, vol. 58, no. 1-4, pp. 411420, 2012.

[41] Iran Khodro Inc, Runna photo gallery, 2014, http://www.ikco.ir/ en $/$ Product.aspx ID $=181 \&$ Section $=4 \&$ Series=Runna. 

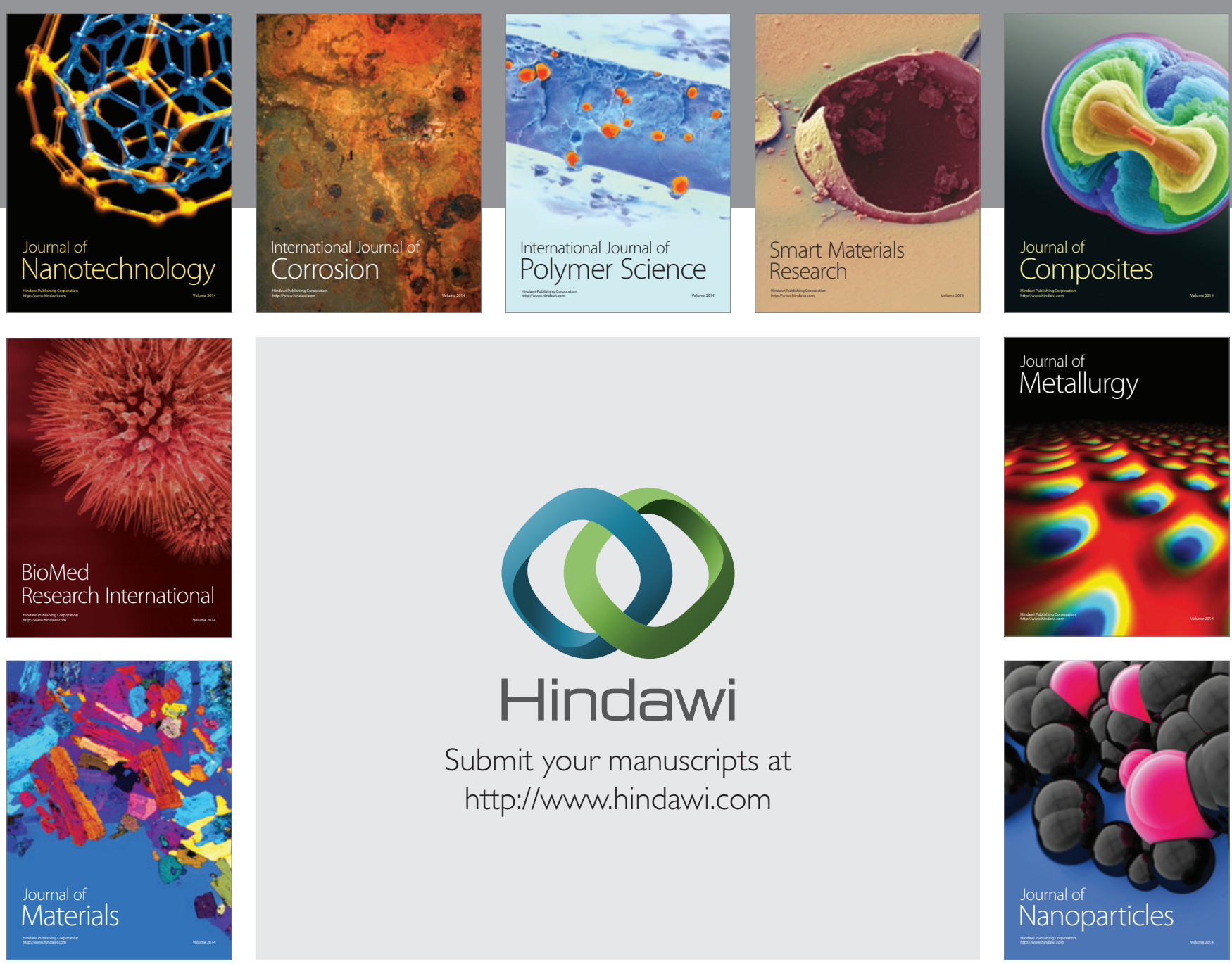

Submit your manuscripts at http://www.hindawi.com
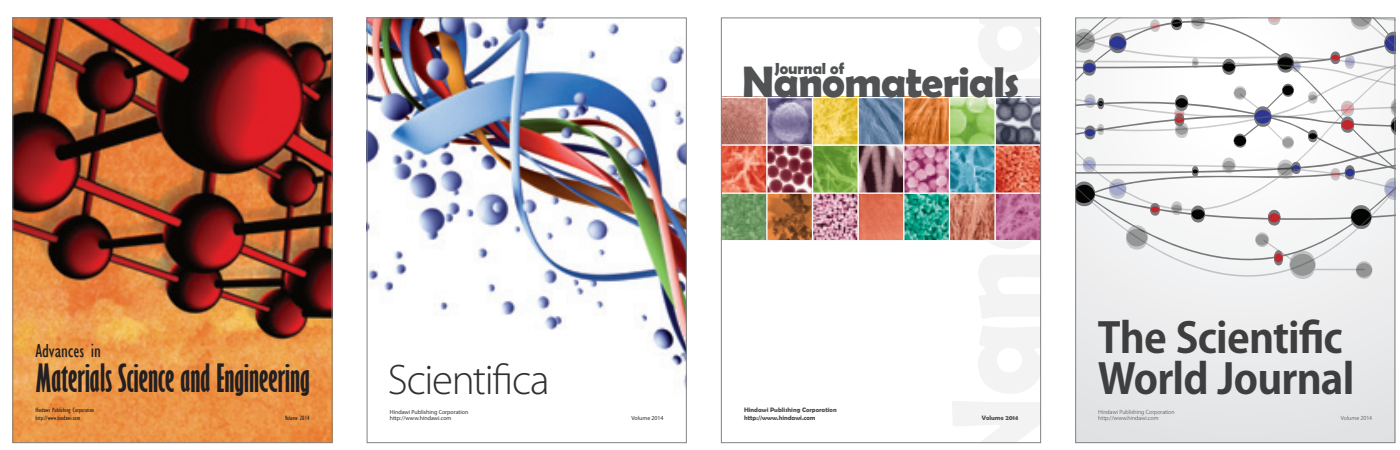

\section{The Scientific World Journal}
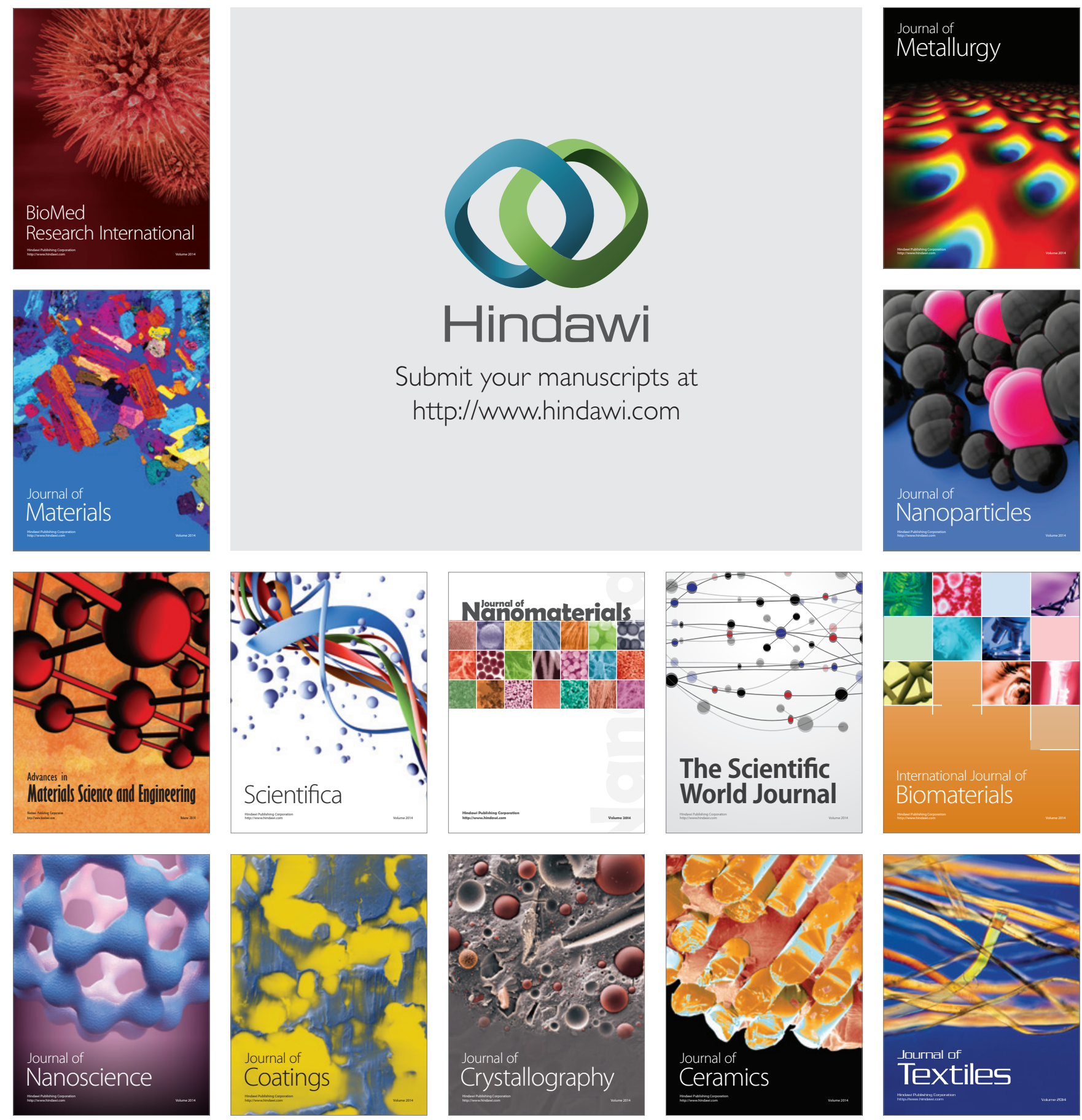